\title{
Doing internet governance: practices, controversies, infrastructures, and institutions
}

\section{Dmitry Epstein}

Department of Communication, University of Illinois at Chicago, United States, dmitry@uic.edu

\section{Christian Katzenbach}

Alexander von Humboldt Institute for Internet and Society (HIIG), Berlin, Germany,

katzenbach@hiig.de

\section{Francesca Musiani}

Institute for Communication Sciences of the CNRS, Université Paris-Sorbonne, France,

francesca.musiani@cnrs.fr

Published on 29 Sep 2016 | DOI: 10.14763/2016.3.435

Abstract: This special issue makes an argument for, and illustrates, the applicability of a science and technology studies (STS) informed approach to internet governance research. The conceptual framework put forward in this editorial and the articles composing this issue add to the mainstream internet governance scholarship by unpacking macro questions of politics and power. They do so through the analysis of the mundane and taken-for-granted practices and discourses that constitute the design, regulation, maintenance, and use of both technical and institutional arrangements of internet governance. Together, this body of work calls to rethink how we conceptualise both internet and governance.

Keywords: Internet governance, Science and technology studies (STS), Internet infrastructure

\section{Article information}

Received: 12 Sep 2016 Reviewed: 19 Sep 2016 Published: 29 Sep 2016

Licence: Creative Commons Attribution 3.0 Germany

Competing interests: The author has declared that no competing interests exist that have influenced the text.

URL:

http://policyreview.info/articles/analysis/doing-internet-governance-practices-controversies-infrastruct ures-and-institutions

Citation: Epstein, D. \& Katzenbach, C. \& Musiani, F. (2016). Doing internet governance: practices, controversies, infrastructures, and institutions. Internet Policy Review, 5(3).

https://doi.org/10.14763/2016.3.435 


\section{PAPERS IN THIS SPECIAL ISSUE}

Doing internet governance: how science and technology studies inform the study of internet governance

Dmitry Epstein, University of Illinois at Chicago, United States

Christian Katzenbach, Humboldt Institute for Internet and Society (HIIG), Germany

Francesca Musiani, Université Paris-Sorbonne, France

Disclosing and concealing: internet governance, information control and the management of visibility

Mikkel Flyverbom, Copenhagen Business School, Denmark

Beyond "Points of Control": logics of digital governmentality

Romain Badouard, Université de Cergy-Pontoise, France

Clément Mabi, Université de Technologie de Compiègne, France

Guillaume Sire, Université Paris II (Panthéon-Assas), France

Instability and internet design

Sandra Braman, Texas A\&M University, United States

The problem of future users: how constructing the DNS shaped internet governance

Steven Malcic, University of California Santa Barbara, United States

The myth of the decentralised internet

Ashwin J. Mathew, University of California, Berkeley, United States

The invisible politics of Bitcoin: governance crisis of a decentralised infrastructure Primavera De Filippi, Harvard University, United States

Benjamin Loveluck, Télécom ParisTech (Université Paris-Saclay) and CERSA (CNRS-Paris 2), France

Multistakeholder governance processes as production sites: enhanced cooperation "in the making"

Julia Pohle, Berlin Social Science Center (WZB), Germany

Internet governance as 'ideology in practice' - India's 'Free Basics' controversy

Anita Gurumurthy, IT for Change, India

Nandini Chami, IT for Change, India

What we talk about when we talk about cybersecurity: security in internet governance debates

Josephine Wolff, Rochester Institute of Technology, United States

Governing the internet in the privacy arena

Carsten Ochs, Universität Kassel, Germany

Fabian Pittroff, Universität Kassel, Germany

Barbara Büttner, Universität Kassel, Germany

Jörn Lamla, Universität Kassel, Germany 


\section{DOING INTERNET GOVERNANCE: HOW SCIENCE AND TECHNOLOGY STUDIES INFORM THE STUDY OF INTERNET GOVERNANCE}

\section{INTRODUCTION: INTERNET GOVERNANCE AS USUAL - AND ITS BLIND SPOTS}

The trajectory of internet governance (IG) research is arguably a story of path dependencies. Starting with the technical design, the early history of internet technology, and internet-related decision-making (Braman, 2011), the trajectory was set for both the kinds of questions being asked and the kinds of disciplinary approaches used in IG research. As van Eeten and Mueller describe it, IG has been shaped by the very real politics and controversies surrounding the "global coordination of Internet domain names and addresses" (2013, p. 724), which are an important, but not the sole factor affecting the internet. Substantively, this research path has focused primarily on institutions such as the Internet Corporation for Assigned Names and Numbers (ICANN), on largely UN processes such as the World Summit on the Information Society (WSIS) and the Internet Governance Forum (IGF), and on the idea of multistakeholderism as a model for internet-related policy decision-making. Conceptually, the field has been dominated by legal scholarship, and by research based in international relations and institutional economics theory, most of which is focused on the role of the nation state in the management of critical internet resources (also see DeNardis, 2010, 2013).

The mainstream view of IG research is being increasingly criticised for its narrow focus on formal institutions, the role of the state, and for missing the mark on what constitutes governance in a networked environment. Van Eeten and Mueller, for example, suggest that the scope of IG research is much wider than what is being labeled as such. They argue that researchers working in areas of telecommunication policy, information security, and cyberlaw all do IG research, even though they are avoiding the label. Conceptually, they suggest rethinking the IG label to include "the diversity of governance on the internet" including "environments with low formalization, heterogeneous organizational forms, large number of actors and massively distributed authority and decision-making power" (2013, p. 730). Substantively, they call to study the economics and practices of organisations that are engaged in managing information flows on the internet, be it in names and numbers, security, or content filtering.

In a similar vein, DeNardis $(2010,2013)$ has criticised mainstream IG research for largely overlooking private arrangements of power when it comes to routing, interoperability, standard setting or content filtering online. Raymond and DeNardis, taking a rather techno-centric view, have argued for a broader umbrella for IG studies - one that would expose those private arrangements of power in IG. Conceptually, their framework spans six functional areas ranging from "control of critical internet resources" to "architecture-based intellectual property rights enforcement" (2015, pp. 589-594) - all of which focus on the praxis of IG as opposed to discourse about IG, which they view as a weakness of mainstream IG research. Substantively, they identify a series of institutions that host decision-making activities (e.g., policy, standards) as points of control for online information flows. 
While the call for expanding the IG label warrants thoughtful consideration, the newly proposed directions remain conceptually and substantively focused on the institutional level of analysis. Indeed, focusing on the institutional or organisational levels of analysis enables the conceptual interrogation both in terms of international relations or institutional economics theories. It is also conveniently compartmentalised for empirical investigation, since most institutions have established boundaries and membership, as well as formal procedures, outcomes, and documentation, all of which are ripe for analysis (van Eeten \& Mueller, 2013). However, the focus on institutions as agents largely overlooks the mundane practices that make those institutions tick, thus leaving important blind spots in both conceptual and substantive understanding of the practices and power arrangements of IG. The focus on institutions and formal policy instruments makes it harder to empirically analyse the diverse forms of internetrelated decision-making and coordination activities that take place outside of formal and well defined boundaries (Musiani, 2015; van Eeten \& Mueller, 2013). Treating institutions as given may overlook institutional change and does not account for functional and structural biases embedded in existing institutional arrangements (Hofmann, Katzenbach, \& Gollatz, 2016; Ziewitz \& Pentzold, 2014). Moreover, the institutional focus obscures the agency of technology designers, policy-makers, and users as those interact, in a distributed fashion, with technologies, rules, and regulations, leading to unintended consequences with systemic effects (Epstein, 2015; Musiani, 2015). Even though researchers such as van Eeten \& Mueller (2013) mention the importance of human agency, IG researchers shy away from empirically analysing or incorporating it in conceptualisation of internet governance. This critique gains additional weight when one adopts a broad definition of IG such as "decision making with constitutive (structural) effect whether it takes place within the public or private sectors, and formally or informally" (Braman, 2009, p. 3) or even just recognises that governance "may be just a side effect of actions with non-governance-related aims" (Hofmann et al., 2016, p. 4).

Tackling the macro questions of politics and power related to IG requires unpacking the micro practices of governance as mechanisms of distributed, semi-formal or reflexive coordination, private ordering, and use of internet resources. Similarly to a scientific lab where "scientific order is constructed out of chaos" (Latour \& Woolgar, 1986, p. 33), seemingly stable arrangements of IG arise from the chaos of taken for granted, mundane, and often apparently unrelated activities of internet design, regulation, and use. It is this focus on practices and routines, discourses and design that makes us talk about the doing of internet governance: as an “accomplishment embedded in everyday interaction" (West \& Zimmerman, 1987, p. 125).1 Continuing the trajectory set by a number of recent arguments for broader use of social theory in making sense of IG (Flyverbom, 2010; Hofmann et al., 2016; Musiani, 2015; Ziewitz \& Pentzold, 2014), this issue argues for adopting a science and technology studies (STS) lens as a way for unpacking the fuzzily defined black box of IG.

In the next section we explain how an STS lens can help addressing some of the blind spots left by institutional and state-centric takes on IG, including functional and structural biases, and how it can foreground the agency of human actors. We will then conclude with presenting papers in this special issue and articulating how they help moving the field of IG research forward.

\section{BRINGING STS IN - DOING INTERNET GOVERNANCE}

The field of science and technology studies has developed a set of concepts and sensibilities (Law, 2008; Law \& Singleton, 2013) that not only addresses the role of technology within the 
social, as it is often highlighted, but also what it means to study social order proper. In contrast to classical social theory, which is at the basis of international relations and institutional economics approaches, this perspective does not assume the existence of such an order that needs to be analytically re-constructed (Wagner, 1994, p. 274-276; Latour, 2005, p. 5-8) - or politically changed by means of regulation. Instead, STS scholars consider the social an "effect generated by heterogeneous means“ (Law, 1992, p. 382), thus making continuous processes of ordering - of economic, political, discursive, technical or other nature 2 - the main focus of scientific inquiry. In this context, governance is broadly understood as social ordering, which does not happen exclusively in politically designed institutions, but is also enacted through mundane practices of people engaged in maintaining or challenging the social order (Woolgar \& Neyland, 2013).

For the field of IG, such an approach to the study of social order implies new ways to question, and re-assemble what we think of as the internet (as in, the set of technologies and protocols) and of governance (as in, broad processes of social order). First, an STS lens lends itself particularly well to considering the internet beyond "critical infrastructure" and a limited number of institutions and processes such as ICANN, IETF, WSIS or IGF (Van Eeten \& Mueller, 2013; DeNardis, 2012). For example, studying IG related controversies (Pinch \& Leuenberger, 2006) is one STS-informed way to unpack the scope of what is meant by internet in IG. Interconnection agreements between internet service providers (Meier-Hahn, 2015), the debate around net neutrality (Marsden, 2010), the use of deep-packet-inspection (Mueller, Kuehn, \& Santoso, 2012) and content filtering technologies (Deibert \& Crete-Nishihata, 2012), ubiquitous surveillance measures and the use of DNS for regulatory aims (DeNardis \& Hackl, 2015) are just a few examples for key sites of contestation over what we think of as our object of study - the internet.

Second, the sensibility for social order as continuous and contested processes translates into a growing attention to the mundane practices of all those involved in providing and maintaining, hacking and undermining, developing and testing, or simply using the network of networks (Musiani, 2015), thus expanding the notion of governance in IG. These diverse practices are not seen as mere objects of regulation, but as elements constitutive to articulating, reifying and challenging established, emerging or contested norms - it is the "doing" of IG. As such, at an analytical level, borrowing from the rich STS tradition of studying the scientific enterprise (e.g. Latour \& Woolgar, 1986), this ensemble of invisible work and mundane practices is not treated markedly separate from the designated IG institutions. Thus, IG as a continuously emerging and dissolving order, in this view, is - rephrasing John Law (1992, p. 382) - an effect generated by heterogeneous means. Moreover, conceptually, an STS lens relieves the pressure of pursuing a single precise definition of internet governance as a prerequisite to meaningful enquiry (Ziewitz \& Pentzold, 2014). Instead, STS approaches mostly consider that not only is it not necessary to provide one precise definition and perimeter of IG, but that the assumptions derived from this operation may go to the detriment of apprehending how the practice of internet governance is enacted, in pervasive, networked and often invisible ways.3

\section{KEY ASPECTS OF DOING INTERNET GOVERNANCE}

Applying the STS lens to IG studies is not entirely new. In recent years, a growing body of STSgrounded IG research (e.g., DeNardis, 2009, 2014; Flyverbom, 2010; Hofmann et al., 2016; Mueller, Kuehn, \& Santoso, 2012; Musiani, 2015; Ziewitz \& Pentzold, 2014) has brought to the fore a number of important IG facets and complexities that haven't been the focus of research 
grounded in political and legal scholarship. The aspects of doing IG highlighted in STS-informed scholarship start with drastically different conceptual frameworks and lean on specific approaches to research cases, sites, and questions. Conceptually, STS-informed IG research relies on understanding IG as a normative 'system of systems' and it acknowledges the agency, often discrete and pervasive, of both human and non-human actors and infrastructures. Empirically, STS-informed IG research focuses on the dynamics of 'ordering' of assemblages and hybrid arrangements of IG; on the structural and performative effects of controversies and de-stabilisations on norm- and decision-making, or on the construction of authority and trust; and finally, on hybrid forums, private arrangements, users and their practices. All these components help flesh out the 'doing' of IG and may be of use in revisiting central, yet illdefined, concepts such as multi-stakeholderism. Below, we unpack each one of those key aspects.

IG as a normative 'system of systems'. Technical and political governance are becoming more and more intertwined. The core issue for scholars of IG at the present stage is to acknowledge not only the plurality of these modes of governance, but the fact that they cannot be fully separated. STS approaches plead for an understanding of internet governance as coexistence of different types of norms, elaborated in a variety of partially juxtaposed forums, enforced, implemented or merely "suggested" via a plurality of normative systems: law, technology, markets, discourses, and practices (Brousseau, Marzouki, \& Méadel, 2012).

Ordering vs regulation (and "back to the institutions"). Acknowledging the diverse origins of norms relevant for the use and design of the internet, most STS-informed IG researchers base their understanding of governance in ordering instead of regulation, management or control.4 As opposed to these concepts, ordering not only captures the normative effect of mundane practices and daily routines, it is also considered particularly well-suited to the analysis of the organisational forms of global politics as assemblages - hybrid configurations constantly reshaping their purposes and procedures in order to connect and mobilise objects, subjects and other elements, constituted and positioned relationally, around particular issues. In this light, institutions of IG can also be explored with an STS-informed toolbox, by capturing the complexity of global "political" governance arrangements as sets of embedded practices (Flyverbom, 2011).

Agency of non-human actors and infrastructures as loci of mediation. Information intermediaries, critical internet resources, internet exchange points, surveillance and security devices play a crucial governance role alongside political, national and supra-national institutions and civil society organisations (Musiani, Cogburn, DeNardis, \& Levinson, 2016). IG takes shape through a myriad of infrastructures, devices, data fluxes and technical architectures that are often discreet and invisible, yet nevertheless crucial in subtending building the increasingly public and articulate network of networks. Laura DeNardis (2014, p. 11) defines these entities as infrastructural "control points", around which are entangled matters of technical and economic efficiency, as well as negotiations over human and societal values such as intellectual property rights, privacy, security, transparency. Recent scholarly and policy discussions on "Governing Algorithms" connect with this aspect, and explore not only governance of algorithms, but also the governing power of algorithms themselves (Ziewitz, 2016; Musiani, 2013).

Mundane practices and agency of human actors. Contrary to the institutional approaches to IG, STS-informed scholarship acknowledges the role of invisible, mundane, and taken-forgranted practices in the constitution of design, regulation, and use of technology. It calls the 
attention to reflexive acts of individuals in articulating internet standards (Braman, 2011), the social aspects of crafting and enacting internet-related policy (Epstein, 2011; Kuerbis, 2010), as well as institutionalisation of non-traditional forms of participation in discourse about IG issues (i.e. multi-stakeholderism), and mechanisms for civic engagement (Epstein, 2013; Nonnecke, 2016). As such it pays the necessary attention to the social - and not just political - aspects of the socio-technical systems of the internet.5

Controversies as structuring and performative processes. STS-informed approaches to IG analyse the structuring and performative effects of controversies on governance. Most prominently, controversies around claims made by different actors or groups about doing IG contribute to the creation of different worlds in which specific notions of governance make sense. Thus, the study of controversies unpacks 'governance' as a theoretical and operational concept, by exposing the plurality of notions it refers to, and the consequences of their being in conflict (Cheniti, 2009; Ziewitz \& Pentzold, 2014). The very processes by which norms are created, re-negotiated, put to the test, re-aligned, raise conflicts, are as crucial - and perhaps more crucial - in STS perspectives as the "stabilised" norms themselves. The authority of IG institutions should also be analysed as such if we are to avoid an understanding of it as a 'fait accompli' (Flyverbom, 2011).

Hybrid forums, privatisation, users... enriching and revisiting 'multi-stakeholderism'. Several concepts brought in by the STS toolbox, as well as several fieldwork choices, can help unveiling a number of situated practices on, by and for the internet that arguably constitute a vital part of 'doing internet governance'. In particular, they help enriching and revisiting the concept of multi-stakeholderism (Malcolm, 2008). For example, understanding IG through the lens of Michel Callon et al.'s 'hybrid forums' (2009) - entities meant to transform controversies into productive dialogue and bring about democracy - show the importance of actors' positioning in subsequent decision-making. If the role of the private sector is more and more important in internet governance arrangements, as it is increasingly widely acknowledged, the technologyembedded nature of its intervention can be brought to the foreground by STS methods. Examining the relationship of internet users to content they put online or consume, to their devices and the values they embed, 'does' governance inasmuch as it reflects belonging and commitment to a set of norms and to a community in a broad sense, and reveals the interplay of issues of sovereignty, autonomy, and civil liberties (Elkin-Koren, 2012).

\section{CONTRIBUTIONS TO THIS SPECIAL ISSUE}

We view this special issue as an important milestone in the broader intellectual project seeking to leverage STS-informed conceptual and empirical toolsets to push the boundary of IG research. This work does not wish to directly criticise or question mainstream IG research. Instead it seeks to add to existing scholarship by focusing on the mundane, situated practices of designing, maintaining, regulating, and using the internet - the aspects of governance that are often overlooked or taken for granted. The papers in this issue cover a broad area of doing IG ranging from concepts and modes of internet ordering, through investigating the link between politics of internet infrastructure and infrastructure as internet politics, to unpacking processes of discourse production and issue framing in IG. Taken together they offer conceptual and empirical contributions that we hope will fuel discussions on how we think about both internet and governance in the context of IG.

The first set of papers engages with concepts and modes of ordering. Mikkel Flyverbom 
highlights information control and the "management of visibility" as a form of governance. In this view, the current trend to seemingly more transparency is only one side of the coin. In most cases, he argues, transparency reports and big data analytics are disclosing as much information as they conceal. More broadly, this allows to uncover the largely invisible ways in which digital infrastructures and architectures institutionalise and normalise particular forms of seeing, knowing and governing. Romain Badouard, Clément Mabi, and Guillaume Sire recondition Foucault's concept of governmentality in order to analyse the power and control exercised by platform providers and developers. They are able to show that power not only rests in more or less obvious 'points of control', but that it is often exercised more subtly by directing, constraining and framing routine online behaviour through specific forms of website design or frameworks for the development of apps. Taken together, both papers highlight the largely invisible aspects of IG. They demonstrate that institutions such as ICANN, IETF, WSIS, and IGF are only the tip of the iceberg, while governance is rooted in far more pervasive - yet discrete in the eyes of the user - mechanisms of power and control.

Drawing STS approaches' suitability to analyse in a detailed and situated fashion the design, construction, establishment, and appropriation of technology, a second set of papers explores the connections between the politics of internet infrastructure and infrastructure as internet politics. In a contribution that is both a precious historical effort and an innovative perspective on early internet design as policy, Sandra Braman draws from a large-scale analysis of the Internet Engineering Task Force's Requests for Comments to explore early internet engineers' techniques to cope with constant change and instability in conceptual labour, social practices, technical approaches, and definitions themselves. In essence, she argues, this coping work constitutes the early internet's policymaking. Early internet designers are also at the core of Steven Malcic's contribution. Grounding his thorough and original archival work in social constructivism and path dependency theory, the author explores the daily struggle of early engineers of the Advanced Research Project Agency Network (ARPANET) to keep this precursor of today's internet in working order. Malcic argues that these designers started doing an ante litteram internet governance work to solve a fundamental problem of design: the need to address future users. Ashwin J. Mathew also touches upon internet infrastructure design in his analysis; in a piece that is sure to spark discussion, he argues that current internet experiences of "apparent decentralisation" are constructed over an infrastructure which was never decentralised, nor designed with decentralisation as a goal. Using the Border Gateway Protocol as a case study, Mathew argues that responses to current concentrations of power of the net cannot rely on technology alone as a mechanism for eliminating centralised control; socially desirable outcomes should be pursued by combinations of political and technological interventions, at different layers of the internet. A similar argument is put forward by Primavera De Filippi and Benjamin Loveluck in their piece on the interplay of technical, social and political governance of Bitcoin. In today's context of frequent hype surrounding blockchain technology, praising in particular its capacity to entirely self-regulate via the algorithm it subtends, the authors use the late 2015/early 2016 controversy over the Bitcoin XT fork to illustrate the limitations of over-reliance on purely technical tools to address complex issues of governance, including elements of social coordination and economic exchange.

A third and final set of papers focuses on processes of discourse production and issue framing in internet governance, exploring them as sites of social ordering where worlds, definitions, meanings, and alliances are co-produced. Julia Pohle draws upon her in-depth observation of the United Nations Working Group on Enhanced Cooperation, and upon theoretical approaches including actor-network theory and interpretive policy analysis, to innovatively contribute to the study of multistakeholder policy-making. By focusing on actors' positionings and on processes 
rather than outcomes - she argues - it is possible to show the validity of the results of multistakeholder processes albeit in the absence of binding outcomes. Using as a case study the 'Free Basics' controversy in India - one of the most telling examples, in recent times, of issues surrounding net neutrality and zero-rating policies - Anita Gurumurthy and Nandini Chami seek to "recover[...] from social practice the contested meanings of the internet". The authors discuss the discursive and material practices uncovered in the Free Basics case - in particular the conflicting notions of access used in the debate - in light of their meaning for internet governance, especially in terms of the challenge they pose to dominant discourses of economic globalisation. What Gurumurthy and Chami do for access, Josephine Wolff does for security: while actors in the IG/cybersecurity space generally agree that the improvement of internet security is an important goal, she argues, the word has different meanings to different stakeholders. This ambiguity, she stresses, is actually crucial to maintaining a functional multistakeholder governance model, as it lends itself well to negotiation and discussion, contributing to the very fabric of consensus; however, this implicit difference in meanings greatly complicates the search for solutions. Carsten Ochs, Fabian Pittroff, Barbara Büttner, and Jörn Lamla mobilise social worlds theory to revisit debates on privacy and data security. Their case studies of the Schengen/National Routing (SNR) proposal and the German Parliamentary Committee investigating NSA activities illustrate how policy and governance heavily rely on translating contested issues into a shared set of frames, thus lending sense and legitimacy to proposed solutions. Interestingly, their findings suggest a strong dominance of the routines and frames of the nation state - despite the global nature of the issues investigated.

\section{CONCLUSION}

Answering recent calls for broader use of social theory in making sense of IG, this special issue makes an argument for, and illustrates, the applicability of an STS lens to the study of IG. Taken together, the STS framework put forward in this editorial and the articles composing this issue break away from the path dependency of IG research by unpacking macro questions of politics and power through the analysis of practices and discourses that constitute design, regulation, maintenance, and use of both technical and institutional arrangements of IG. As such, this body of work calls to rethink how we conceptualise both internet and governance.

When examined through the STS lens, the internet does not constitute a given, static technological development that needs to be regulated. Instead, the very fibre cables, routers, protocols, and all the other technological elements of the network of networks constitute, perpetuate, and contest order in the first place. In other words, implementation of seemingly technical decisions about the technological design of the network and its operating rules, which are often opaque for the user, constitute a facet of governance itself. But it is not only those decisions, even in combination with formal law and regulation, that draw a complete and nuanced picture of governance when IG topics are examined through the lens of STS. STSinformed IG research pushes further, by unpacking seemingly stable black boxes of technology and regulation through observation and analysis of apparently unrelated activities of internet design, regulation, and use. Some of these activities are deliberately deployed to regulate, but most of them are rather mundane and taken-for-granted routines.

The articles in this issue demonstrate how technical decisions may have a constitutive effect by encoding values, normalising and institutionalising norms of knowing, or by directing online behaviour. At the same time, they unveil the very social nature of the technology design endeavour by showing how technical decisions are intimately intertwined with the social and 
cultural contexts of their design, and in many cases are dependent on inherently social and political arrangements of trust and consensus. In addition, articles in this collection bring forward the role of deliberation and discursive reflection as constitutive forces in dealing with specific internet policy related issues as well as in establishing norms and propagating unique forms of governmentality for the ordering of the internet.

The STS lens presented in this volume does not necessarily negate or reject previous IG research that is mainly focused on the institutional level and the role of the state. Instead it unpacks some of the elements that are considered as constant or static when the object of analysis is an institution or a state as a whole. The STS lens enables to connect the micro actions of individuals and the affordance of particular technical artifacts with emergent attributes of large, complex systems. As such, it adds a layer of complexity and dynamics, thus allowing to ask more nuanced questions about arrangements of power in IG. The focus on individual cases and particular contexts can be criticised for its limited generalisability and the challenge of validating empirical claims. Yet, this perceived weakness of conducting research on the micro scale can also be viewed as an important opportunity to validate assumptions and observations made about the internet and its governance as a whole. The very focus on detail, specific cases, and controversies offers important ecological validity, often missing in research that takes a more general stance.

If we use the proverbial dark alley - where a man is searching for his keys under a streetlamp only because this is the only lit spot - as an allegory for IG research, this issue adds another lamppost. The STS perspective we develop here offers new perspectives on issues that have been examined before, illuminates previously overlooked aspects of IG, enables asking new questions, and offers new methodological ways of doing that. Of course, just as any other conceptual or methodological approach, the STS toolkit has its limitations and is subject to valid criticism, but together with the existing (and thriving) body of IG work, it makes the dark alley of research in this field a little better lit. 


\section{REFERENCES}

Borras, S. \& Edler, J. (2014, eds.) The Governance of Socio-Technical Systems. Cheltenham, UK: Edward Elgar.

Braman, S. (2009). Change of state: Information, policy, and power. Cambridge, MA: MIT Press.

Braman, S. (2011). The framing years: Policy fundamentals in the Internet design process, 1969-1979. The Information Society, 27(5), 295-310. doi: 10.1080/01972243.2011.607027

Brousseau, E., Marzouki, M. \& Méadel, C. (eds., 2012). Governance, Regulation and Powers on the Internet. Cambridge : Cambridge University Press.

Callon, M., Lascoumes, P. \& Barthe, Y. (2001). Agir dans un monde incertain. Essai sur la démocratie technique, Paris: Seuil.

Cheniti, T. (2009). Global Internet Governance in Practice. Mundane Encounters and Multiple Enactments. Unpublished DPhil Thesis, University of Oxford.

Deibert, R. J., \& Crete-Nishihata, M. (2012). Global governance and the spread of cyberspace controls. Global Governance: A Review of Multilateralism and International Organizations, 18(3), 339-361.

DeNardis, L. (2010). The privatization of internet governance. Presented at the Fifth Annual GigaNet Symposium, Vilnius, Lithuania.

DeNardis, L. (2012). Hidden levers of internet control. An infrastructure-based theory of internet governance. Information, Communication \& Society, 15(5), 720-738.

DeNardis, L. (2013). The emerging field of internet governance. In W. H. Dutton (Ed.), The Oxford handbook of Internet studies (pp. 555-576). Oxford, UK: Oxford University Press. doi: 10.1093/oxfordhb/9780199589074.013.0026

DeNardis, L. (2014). The Global War for Internet Governance. New Haven, CT and London: Yale University Press.

DeNardis, L., \& Hackl, A. M. (2015). Internet governance by social media platforms.

Telecommunications Policy. doi:10.1016/j.telpol.2015.04.003

Elkin-Koren, N. (2012). Governing Access to User-Generated Content : The Changing Nature of Private Ordering in Digital Networks. In Brousseau, E., Marzouki, M., Méadel, C. (eds.), Governance, Regulations and Powers on the Internet (pp. 318-343). Cambridge : Cambridge University Press.

Epstein, D. (2011, September). Manufacturing Internet policy language: The inner workings of the discourse construction at the Internet Governance Forum. In 39th Annual Telecommunication Policy Research Conference. Arlington, VA.

Epstein, D. (2013). The making of institutions of information governance: The case of the Internet Governance Forum. Journal of Information Technology, 28(2), 137-149.

Epstein, D. (2015). Duality squared: On structuration of Internet governance. In R. A. Lind 
(Ed.), Produsing Theory in a Digital World 2.0 (pp. 41-56). New York, NY: Peter Lang Publishing.

Flyverbom, M. (2011). The Power of Networks: Organizing the Global Politics of the Internet. Cheltenham, UK : Edward Elgar Publishing.

Flyverbom, M. (2010). Hybrid networks and the global politics of the digital revolution - a practice-oriented, relational and agnostic approach. Global Networks, 1O(3), 424-442. doi:10.1111/j.1471-0374.2010.00296.x

Hofmann, J., Katzenbach, C., \& Gollatz, K. (2016). Between coordination and regulation: Finding the governance in Internet governance. New Media \& Society.

doi:http://doi.org/10.1177/1461444816639975

Latour, B. (2005). Reassembling the social: An introduction to actor-network-theory. Oxford: Oxford Univ. Press.

Latour, B., \& Woolgar, S. (1986). Laboratory life: The construction of scientific facts (2nd edition). Princeton, N.J: Princeton University Press.

Law, J. (1992). Notes on the theory of the actor-network: Ordering, strategy, and heterogeneity. Systems Practice, 5(4), 379-393.

Law, J. (2008). On sociology and STS. The Sociological Review, 56(4), 623-649.

Law, J., \& Singleton, V. (2014). ANT, multiplicity and policy. Taylor \& Francis. doi:10.1080/19460171.2014.957056

Kuerbis, B. (2010, August). Influencing internet governance through social networks and delegation: The case of secure routing. In 38th Annual Telecommunication Policy Research Conference. Arlington, VA.

MacLean, D. (2004). Herding Schrödinger's cats: Some conceptual tools for thinking about internet governance. In Don MacLean (Ed.), Internet Governance: A Grand Collaboration (pp. 73-99) (ICT Task Force Series 5), New York, NY.

Malcolm, J. (2008). Multi-Stakeholder Governance and the Internet Governance Forum. Wembley, WA : Terminus Press.

Marsden, C. (2010). Net Neutrality: Towards a Co-Regulatory Solution. Bloomsbury USA.

Meier-Hahn, Uta (2015, February 5). Internet Interconnection: Networking in Uncertain Terrain [Blog post]. RIPE Labs. Retrieved from

https://labs.ripe.net/Members/uta_meier_hahn/internet-interconnection-networking-in-unce rtain-terrain.

Mueller, M. L., Kuehn, A., \& Santoso, S. M. (2012). Policing the network: Using DPI for copyright enforcement. Surveillance \& Society, 9(4), 348-364.

Musiani, F. (2013). Governance by algorithms. Internet Policy Review, 2(3).

doi:10.14763/2013.3.188

Musiani, F. (2015). Practice, Plurality, Performativity and Plumbing : Internet Governance 
Research Meets Science and Technology Studies. Science, Technology and Human Values, 4O(2): 272-286.

Musiani, F., Cogburn, D. L., DeNardis, L. \& Levinson, N. S. (2016, eds.). The Turn to Infrastructure in Internet Governance. New York: Palgrave/Macmillan.

Nonnecke, B. M. (2016). The transformative effects of multistakeholderism in Internet governance: A case study of the East Africa Internet Governance Forum. Telecommunications Policy, 4O(4), 343-352. doi:10.1016/j.telpol.2015.12.005

Pinch, T., \& Leuenberger, C. (2006). Studying scientific controversy from the STS perspective. Presented at the Science Controversy and Democracy, Taipei, Taiwan.

Raymond, M., \& DeNardis, L. (2015). Multistakeholderism: Anatomy of an inchoate global institution. International Theory, 7(3), 572-616. doi:10.1017/S1752971915000081

Van Eeten, M. J., \& Mueller, M. (2013). Where is the governance in Internet governance?. New Media \& Society, 15(5), 720-736

Wagner, P. (1994). Dispute, uncertainty and institution in recent french debates. Journal of Political Philosophy, 2(3), 270-289. doi:10.1111/j.1467-9760.1994.tbooo25.x

West, C. and Zimmerman, D. H. (1987). Doing gender. Gender \& Society, 1(2), 125-151.

Woolgar, S., \& Neyland, D. (2013). Mundane governance: Ontology and accountability. Oxford University Press.

Ziewitz, M. (2016). Governing Algorithms: Myth, Mess, and Methods. Science, Technology and Human Values, 41(1): 3-16.

Ziewitz, M. and Pentzold, C. (2014). In Search of Internet Governance: Performing Order in Digitally Networked Environments. New Media \& Society, 16(2): 306-322

\section{FOOTNOTES}

1. Candace West and Don H. Zimmerman (1987) introduced the notion of 'Doing Gender' in order to highlight that gender is neither an individual property nor a fixed social category. Instead it is established, reified, and contested in daily routines and interactions.

2. Only 'social' is not an adjective that belongs here, since the social, in this view, is the effect, not a cause: 'Problems arise, however, when "social" begins to mean a type of material, as if the adjective was roughly comparable to other terms like "wooden", "steely", "biological", "economical”, "mental”, "organizational”, or "linguistic".[...] In this meaning of the adjec-tive, social does not designate a thing among other things, like a black sheep among other white sheep, but a type of connection between things that are not themselves social [...] "Social" is not some glue that could fix everything including what the other glues cannot fix; it is what is glued together by many other types of connectors.' (Latour, 2005: 1;4)

3. A debate is ongoing among scholars of governance of socio-technical systems (including the internet) on the following tension. Getting to a definition of governance, one that helps decide on what is relevant or non-relevant vis-à-vis governance appears desirable for governance to be a useful analytical concept. However, how is it possible to obtain a satisfactory definition without excessively schematising such a complex notion, or constraining it too much in pre- 
conceptions or postulates? Susana Borras and Jakob Edler have recently tackled this question in the volume The Governance of Socio-Technical Systems (Borras \& Edler, 2014).

4. Cf. Flyverbom (2011) for the first substantial application of this concept on matters of IG, and Hofmann et al. (2016) for a discussion of ordering and coordination vis-à-vis regulation.

5. It should be noted that a few researchers self-described as STS scholars of IG debate whether user agency and practice should be included in internet governance. Most notably, Laura DeNardis (2014) disagrees. 